\title{
Personal space: An unobtrusive measures study
}

\author{
EDWARD REID and PATRICIA NOVAK \\ Southern Illinois University at Carbondale, Carbondale, Illinois 62901
}

\begin{abstract}
Two unobtrusive studies were made of male urinal behavior in a public lavatory. It was found that the presence of another male influenced the subject's selection of a urinal. Subjects in all but two cases maintained a distance of at least one urinal between themselves and other individuals present at the urinals. The results are discussed in light of the recent work in the areas of privacy and personal space.
\end{abstract}

There is a growing interest in the conceptual and empirical study of privacy (e.g., Altman, Note 1; Proshansky \& Wolfe, Note 2). Altman (Note 1) discussed personal space as a nonverbal mechanism for maintaining privacy in relation to one's body. The minimum distance an individual can comfortably tolerate between himself and another actor defines that person's personal space. Sommer and his colleagues have studied the notion of personal space in a variety of situations. For example, in a public library and at a state mental institution Felipe and Sommer (1966) found that intrusion into another person's personal space resulted in lower departure latencies for these people relative to control subjects who were observed sitting alone.

Other researchers have been interested in whether individuals adhere to a personal space norm in naturalistic settings. An example of such naturalistic observation comes from Brandeis (1972) who observed the stall behavior in a male and female residence hall lavatory. For males it was found that they preferred the two end stalls over the two center stalls, and when two males were occupying the stalls at the same time (8 cases) there was a tendency for them to avoid sitting in adjacent stalls. The female residence hall contained two rows of four stalls placed against opposite walls. The women showed a definite preference for the two opposite end stalls at the rear of the lavatory. The results of this study were interpreted by the author as reflecting a desire for privacy on the part of the occupants of the stalls. The study reported below deals with male urinal behavior. Based on the foregoing research, it was hypothesized that males would avoid using adjacent urinals.

\section{STUDY I}

\section{Method}

Subjects. The subjects were 263 males who used the lavatory in the Life Sciences II building at Southern Illinois University during the period of observation. These persons were primarily students and faculty connected with the Department of Psychology. Data from situations in which a subject entered when two or more urinals were in use were not analyzed. This reduced the number of subjects to 244 .

Setting. The setting was a $4.0 \times 5.0 \mathrm{~m}$ lavatory that contained four urinals $18 \mathrm{~cm}$ apart along one wall. Along the opposite wall

This manuscript is sponsored by Ronald $R$. Schmeck who takes full editorial responsibility for it. were four stalls. The bathroom also contained three sinks positioned side by side along a third wall.

Procedure. The greatest use of the lavatory facilities was known to occur during the 10-min interval between classes. Shortly before $10 \mathrm{~min}$ to the hour the observer would position himself in one of the stalls directly across from the urinals. Through small openings around the closed stall door all four urinals could be seen by the sitting observer. The observer recorded which urinals were used by the subjects until the onset of the next hour when the data gathering session was terminated. The data were gathered during 34 observation sessions over a 26-day period.

This study fits the criterion of unobtrusive measures research as set forth by Webb, Campbell, Schwartz, and Sechrest (1966) in that it is extremely unlikely that subjects were aware that their behavior was being observed. It was very difficult for subjects to see inside the stalls when the doors were closed and, during many of the observation sessions, at least one of the three remaining stalls was in use which suggests that the presence of the observer would not arouse suspicion. Thus, the possibility of the subject's behaving differently due to awareness that he was being observed was controlled.

\section{Results}

The data (see Table 1) indicated that the urinal most favored by a subject entering the lavatory with none of the urinals in use was Urinal 1. The frequency (99) was significantly different from the number of subjects choosing Urinal $2\left(\chi_{1}\right.$ vs. $2=25.22, p<.001$, as well as frequencies for Urinals 3 and $4 .^{3}$ Urinal 2 also received* more use $(\mathrm{N}=39)$ than Urinals $3(\mathrm{~N}=18)$ and $4(\mathrm{~N}=$ 19); $\chi_{\mathbf{2 d f}}=10.03, p<.01$. When subjects entered with Urinal 1 in use, they tended to select either Urinal 3 or 4 with no clear preference. In this case Urinal 2 was used less often than either Urinal $3\left(\chi_{2}\right.$ vs. $\left.3=8.47 \mathrm{p}<.01\right)$ or Urinal 4 ( $\chi_{2}$ vs. $4=5.78, p<.02$.

All subjects who entered with a person using Urinal 2 went to Urinal $4\left(\chi_{2}^{2} \mathrm{df}=22.19\right.$ using Yates,

Table 1

Data from Study I

\begin{tabular}{lrrrrr}
\hline & \multicolumn{5}{c}{ Urinal Chosen } \\
Person Enters & \multicolumn{1}{c}{2} & \multicolumn{1}{c}{3} & \multicolumn{1}{c}{4} & Total \\
\hline Alone & 99 & 39 & 18 & 19 & 175 \\
With person at 1 & & 2 & 15 & 19 & 36 \\
With person at 2 & 0 & & 0 & 13 & 13 \\
With person at 3 & 9 & 0 & & 0 & 9 \\
With person at 4 & 8 & 3 & 0 & & 11 \\
Total & 116 & 44 & 33 & 51 & 244 \\
\hline
\end{tabular}

Note-Urinal 1 is the urinal closest to the lavatory door. 
$p<.0000019$, exact test. Subjects who entered with a person using Urinal 4 used Urinal 1 more often than Urinal 2, but this difference was not significant $\left(\chi_{1 \text { vs, } 2}=\right.$ 1.45 , ns). All subjects who entered with a person using Urinal 3 went to Urinal $1(\mathrm{p}=.00015$, exact test $)$. In general, there was a marked tendency for persons to avoid using a urinal that was adjacent to one already in use $\left(\chi_{1 \mathrm{df}}=52.40, \mathrm{p}<.001\right)$. A second study was conducted to establish that the results of Study I were not unique to the particular lavatory sampled in Study I (and thus not unique to psychologists and students of psychology).

\section{STUDY II}

\section{Method}

Subjects. Subjects were 64 males who used the lavatory on the first floor of the Faner Building on the campus of Southern Illinois University at Carbondale. This building houses faculty connected with the humanities (e.g., philosophy, English) and its class rooms are used by various departments throughout the university.

Setting and procedure. The setting was a $4.5 \times 5.0 \mathrm{~m}$ bathroom that contained four urinals $20.5 \mathrm{~cm}$ apart. Directly across from the urinals were three stalls, the center stall being occupied by the observer. Otherwise, the procedure for Study II was the same as for Study I. The data were collected during 7 observation sessions over a 3 -day period.

\section{Results}

The small sample size did not permit the same comparisons to be made with Study II data as were done with the data from Study I. However, subjects who entered the bathroom with another person already using a urinal invariably maintained a distance of at least one urinal between themselves and that person $\left(\chi_{1 \mathrm{~d} f}=\right.$ $44.94, \mathrm{p}<.001)$.

\section{DISCUSSION}

In Study I the behavior of a subject entering when no other urinals were in use seemed to be governed more by a principle of least effort than by one of privacy. If the desire for privacy were prepotent, one would expect that Urinal 4 (the one farthest from other lavatory activities) would be the one most often selected. However, Urinal 1 (closest to the door) was the most frequently selected urinal. In Brandeis's (1972) study the desire for privacy seemed to override least effort (at least for females); it could be that defecation is seen as a more private bodily function than urination.

The data reported in these studies are clearly consistent with most of the previous research in the area of personal space (e.g., Felipe \& Sommer, 1966). In Study I, Urinal 1 was the overwhelming favorite for subjects entering the lavatory with nobody else using the urinals. Based strictly on this datum, it would be predicted that subjects would tend to select Urinal 1 whenever it is available. However, the presence of another person at Urinal 2 resulted in every subject selecting Urinal 4 . When Urinal 1 was occupied, all but two subjects passed by Urinal 2, the second most frequently used urinal, in favor of Urinals 3 and 4. Data from Study II were consistent with those of Study I in that subjects invariably avoided adjacent urinals.

It appears that there exists an unspoken personal space norm in lavatory settings. However, interpersonal distance in a lavatory situation is probably not a pure measure of respect for another's personal space. To shun adjacent urinals (or stalls) could reflect a desire to minimize potentially unpleasant olfactory cues as well as a desire to adhere to a personal space norm.

\section{REFERENCES}

Brandeis, H. N. The psychology of scatological privacy. Journal of Biological Psychology, 1972, 14, 30-35.

Felipe, N., \& Somer, R. Invasions of personal space. Social Problems, 1966, 14, 206-214.

Webb, E. J., Campbell, D. T., Schwartz, R. D., \& Sechrest, L. Unobrustive measures: Nonreactive research in the social sciences. Rand McNally, 1966.

\section{NOTES}

1. Altman, I. Privacy: A conceptual analysis. Paper presented at APA Convention, New Orleans, 1974.

2. Laufer, R. S., Proshansky, H. M., \& Wolfe, M. Some analytic dimensions of privacy. Unpublished manuscript, Brooklyn College, CUNY, 1974.

3. The chi square test is based on the assumption that the observations are independent. This assumption is violated by the present data in that some subjects were observed more than once. This limitation should be kept in mind when interpreting the results of Study $I$.

4. When the expected cell frequency in any cell is less than five, the chi-square test is not conservative enough. In such cases, the exact probability of the obtained distribution must be computed. This was done using the nonparametric statistical analysis package (NPAR), Computer Institute for Social Science Research, Michigan State University.

(Received for publication on November 14, 1974.) 